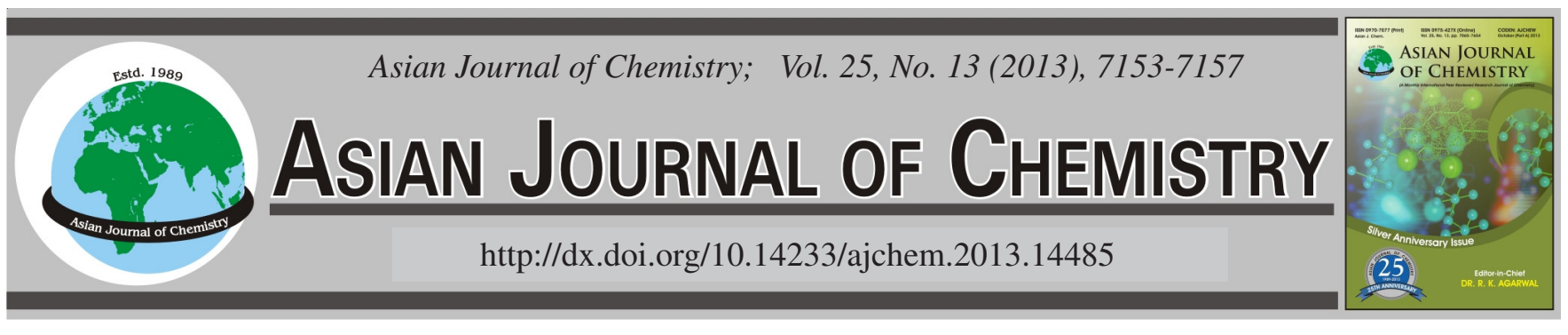

\title{
Flame Retarded Nylon 66 Nanocomposites: Comparing the Effect of Different Flame Retardants on the Flammability
}

\author{
H. Ebadi-Dehaghani ${ }^{*}$, D. Ashori and M. HassanZadeh-Soureshuani
}

Department of Polymer Engineering, Shahreza Branch, Islamic Azad University, Shahreza, Iran

*Corresponding author: Fax: +98 321 3232701-2; Tel: +98 321 3243001-4; E-mail: hassanebadi2003@yahoo.com

\begin{abstract}
The flame retarded nylon 66 nanocomposites was prepared using different flame retardants at equal amount of 5 wt $\%$ of nanoparticles in a co-rotating twin extruder. The compression molded samples were prepared for flame retardancy tests. The SEM images of nanocomposites showed an acceptable dispersion of nanoparticles within the nylon 66 matrix. TGA, DTG and limiting oxygen index results showed that the modified clay had a good performance to increase thermal stability and flame retardancy of nylon 66 comparing to other flame retardant nanoparticles. The residue per cent and the morphology of the char are important factors in flame retardancy. SEM images of residues showed that the nanocomposites containing clay and iron oxide nanoparticles have an honeycomb-like structure in the outer layer that could provide a good barrier to the transfer of heat and mass, which resulted in the improvement of the flame retardancy of nylon 66.
\end{abstract}

Key Words: Nylon 66, Nanocomposite, Flame retardant, Thermal stability.

\section{INTRODUCTION}

Aliphatic nylons are important engineering resins manufactured in large quantities for fiber, film and other applications. Fire retardancy of aliphatic nylons is mostly required in electric industries, with typical applications in electrical connectors, terminal blocks, small electrical housings, clip fasteners, switch components, wire ties and many other industrial parts. The flame retarded polymer nanocomposite is an important branch in polymer nanocomposites. In the 1980s, Nylon-6/clay nanocomposites was synthesized by Toyota Central Research and Development Laboratories and found that a tiny amount of clay can greatly improve the thermal stability and mechanical properties ${ }^{1}$. After that, flame retarded polymer nanocomposites were developed rapidly and has become a "hot spot" in the flame retardation field. Compared with the traditional flame retardants (FR) such as halogen, phosphorous and intumescent flame retardants, polymer nanocomposites have shown dramatic improvements in the mechanical, thermal and barrier properties with a small amount of nano flame retardants (normally $<5 \mathrm{wt} \%$ ). The present flame retarded polymer nanocomposites can be sorted into the following three types according to the dimensionality of nanoparticles: layered materials, such as clay (e.g., montmorillonite: MMT), graphite oxide (GO) and layered doubled hydroxides (LDH), which are characterized by one nanometric dimension, referred to as 2D nanoparticles; fibrous materials, such as carbon nanotubes and whiskers, which are characterized by elongated structures with two nanometric dimensions and referred to as 1D nanoparticles; particulate materials, such as polyhedral oligosilsesquioxane (POSS), fullerene (C60), aluminum hydroxide and spherical silica nanoparticles, which are characterized by three nanometric dimensions and sometimes referred to as $0 \mathrm{D}$ nanoparticles.

Polymer/layered silicate nanocomposites (PLSN) has attracted much attention in the field from both industry and academia. Giannelis et al. ${ }^{2-4}$ found that PLSN can be prepared by direct melt compounding without using organic intercalating agents. Another flame retarder material, graphen oxide, was studied by other researchers. They found that this filler has a potential in retarding the flammability of epoxy resin ${ }^{5}$. A very small amount of nano flame retardants (normally $<5$ wt \%) can significantly reduce the heat release rate (HRR) and smoke emission (SEA) during the combustion of polymer materials. Moreover, the addition of nano flame retardants can also improve the mechanical properties of polymer materials compared with the deterioration of traditional flame retardants. Because the neat nylon 66 with low limiting oxygen index (LOI) value can easily burn, which limits its application in electric and electronic industry, therefore, how to improve the flame retardancy of nylon 66 was the aim of this work. Several types of flame retardants, such as halogen flame retardant and 
phosphorus flame retardant, have been used to improve the flame retardancy of polyamides. However, the application of halogen flame retardant is being greatly limited due to the possible production of dioxin, large amount of smoke and corrosive gases during the combustion of the halogen flame retarded materials. Phosphorus flame retardant also has some drawbacks such as heavy colour, toxicity and high exudation ${ }^{6,7}$. The aim of the present study was to compare the effect of typical flame retardant such as aluminum trihydroxide (ATH), bohemite, $\boldsymbol{\gamma}-\mathrm{Al}_{2} \mathrm{O}_{3}$, clay (modified and non-modified) and $\alpha-\mathrm{Fe}_{2} \mathrm{O}_{3}$ nanoparticles at equal amount of $5 \mathrm{wt} \%$ on the flammability and degradation behaviour of nylon 66. These flame retardants don't have the mentioned problems ${ }^{8}$.

\section{EXPERIMENTAL}

Nylon 66 was Tecnomide NA40 NLE grade (Eurotec Company, Turkey). Aluminum trihydroxide $\left(\mathrm{Al}(\mathrm{OH})_{3}\right)$, bohemite $[\mathrm{AlO}(\mathrm{OH})]$ and aluminum oxide $\left(\gamma-\mathrm{Al}_{2} \mathrm{O}_{3}\right)$ nanoparticles, with a density of $0.25,0.87$ and $0.55 \mathrm{~g} / \mathrm{cm}^{3}$, respectively, was provided by Nano Pars Spadana Co. (Esfahan, Iran) with a mean diameter of $\mathrm{d}=30-40 \mathrm{~nm}$. Two kinds of clay were used: (1) Cloisite $\mathrm{Na}^{+}$was a natural montrmorillonite. It had a density of 2.86 $\mathrm{g} / \mathrm{cm}^{3}$. (2) Cloisite 20A was a natural montrmorillonite modified with a quaternary ammonium salt. It had a density of 1.77 $\mathrm{g} / \mathrm{cm}^{3}$. They supplied by Southern Clay products Inc., USA. $\alpha-\mathrm{Fe}_{2} \mathrm{O}_{3}$ was supplied by Tecnan Company (Spain) and had a density of $5.24 \mathrm{~g} / \mathrm{cm}^{3}$ and a mean diameter of $30 \mathrm{~nm}$.

General procedure: All the materials were dried in an oven at $80{ }^{\circ} \mathrm{C}$ for $12 \mathrm{~h}$ before melt extrusion. Next the nylon 66 pellets and flame retardant nanoparticles (5 wt \%) were dry blended and fed in a ZSK (ZSK 18 Megalab, Germany) co-rotating twin-screw extruder. The mixing was carried out at a rotor speed of $100 \mathrm{rpm}$. The extruded blends were pelletized at the die exit, dried and then compression molded for $2 \mathrm{~min}$, to obtain sheet samples for flame retardency tests. The samples were quenched in the cold press of the compression molding machine. For each type of nanocomposite, as well as for the neat polymer, the same procedure was applied so that the thermo-mechanical history of the nanocomposites and that of neat polymers remain similar for thermal analysis. Hereafter we denote the nylon $66 / \mathrm{Al}(\mathrm{OH})_{3}$, nylon $66 /$ bohemite, nylon $66 / \gamma-\mathrm{Al}_{2} \mathrm{O}_{3}$, nylon $66 / \alpha-\mathrm{Fe}_{2} \mathrm{O}_{3}$, nylon $66 /$ cloisite $\mathrm{Na}^{+}$and nylon $66 /$ cloisite $20 \mathrm{~A}$ containing $5 \mathrm{wt} \%$ of the nanofillers with nylon 66/ATH, nylon 66/BHM, nylon 66/AO, nylon 66/IO, nylon 66/NMC and nylon 66/MC, respectively.

Scanning electron microscopy (SEM): A piece of the compression moulded samples containing $5 \mathrm{wt} \%$ of nanoparticles was cut for SEM studies. The dispersion quality of the nanoparticles within the matrix and the nanostructures of the nanocomposites were investigated using a scanning electron microscope (Seron Technology, AIS-2100 Model, South Korea). The specimens were fractured in liquid nitrogen and coated with gold using a sputter coater, mounted and observed. The fracture surface of the residues for neat nylon 66 and the nanocomposites after combustion was also observed by the SEM.

Limiting oxygen index (LOI): The limiting oxygen index (LOI) is the minimum fraction of $\mathrm{O}_{2}$ and $\mathrm{N}_{2}$ that will just support flaming combustion. Limiting oxygen index data of all samples were obtained at room temperature by a Fire Testing Technology Instrument at a flow rate of $10.6 \mathrm{~L} / \mathrm{min}$ with test specimen bars of $127 \mathrm{~mm}$ in length, $6.5 \mathrm{~mm}$ in width and about maximum up to $3.2 \mathrm{~mm}$ in thickness, according to ASTM D2863 standard.

Thermal analysis: Thermal properties were investigated by a simultaneous thermal analysis instrument (STA), Labsys TG (Setaram Instumentation, France). A piece of the compression molded sample similar to that used for SEM and LOI, with a weight of $8-10 \mathrm{mg}$, was placed into an alumina pan in the presence of nitrogen gas as the furnace atmosphere. Measurements were performed from ambient temperature up to $600{ }^{\circ} \mathrm{C}$ with a heating rate of $10^{\circ} \mathrm{C} / \mathrm{min}$.

\section{RESULTS AND DISCUSSION}

Dispersion of nanoparticles in the matrix: The morphology of nylon 66 nanocomposites was evaluated by SEM to observe the distribution of nanoparticles within the extruded nanocomposites. Fig. 1 shows micrographs of cryofractured surfaces of the nanocomposites. Good nanoparticle dispersion is seen in these micrographs. However partial coalescence was unavoidable. Many particles were larger than the original sizes. These particles had undergone coalescence. A good dispersion of nanofillers within the nylon 66 matrix could improve flame rtardancy of the nanoparticles within the matrix even at low contents owing to enhanced filler-matrix interaction.

Thermal degradation behaviour of nanocomposites: The thermal degradation behaviour is extremely important for flame retarded materials ${ }^{9}$. The thermogravimetry results of nylon 66 and the nanocomposites are shown in Figs. 2 and 3 and Table-1. In regard to pure nylon 66, the degradation temperature at $340-460{ }^{\circ} \mathrm{C}$ is attributed to the depolycondensation and cross-linking reaction ${ }^{8}$. Then at higher temperature, the material degrades slowly and leaves some char residue at $500{ }^{\circ} \mathrm{C}$. In the presence of nanofillers, the enhanced effect on the thermal stability is obvious; the degradation of nylon 66 nanocomposites begins at a higher temperature. $\mathrm{T}_{5} \%$ (the degradation temperature of $5 \%$ weight loss) of the nanocomposites increases compared with that of pure nylon 66. MC was the most successful flame retardant in enhancement of thermal stability. As seen in the TGA thermogram, there was an increase of about $50{ }^{\circ} \mathrm{C}$ in the degradation temperature of the Nylon 66/MC nanocomposite compared with pure polymer. It is corresponded to the better dispersion and also exfoliation in the nylon 66/MC comparing to that of nylon $66 / \mathrm{NMC}^{10}$. The rate of degradation and for this nanocomposite is also lower than Nylon 66/NMC and other nanocomposites but the

TABLE-1

TGA RESULTS OF NYLON 66 AND

NYLON 66 NANOCOMPOSITES

\begin{tabular}{lccc}
\hline \multicolumn{1}{c}{ Sample } & $\mathrm{T}_{5 \%}\left({ }^{\circ} \mathrm{C}\right)$ & $\mathrm{T}_{\max }\left({ }^{\circ} \mathrm{C}\right)$ & Residue at $500{ }^{\circ} \mathrm{C}(\mathrm{wt} \%)$ \\
\hline Nylon 66 & 346.0 & 415.0 & 9 \\
Nylon 66/ATH & 395.0 & 430.4 & 15 \\
Nylon 66/IO & 393.8 & 431.2 & 25 \\
Nylon 66/MC & 422.7 & 451.9 & 30 \\
Nylon 66/NMC & 409.7 & 455.9 & 19 \\
Nylon 66/BHM & 416.7 & 456.2 & 10 \\
Nylon 66/AO & 413.8 & 460.9 & 18 \\
\hline
\end{tabular}




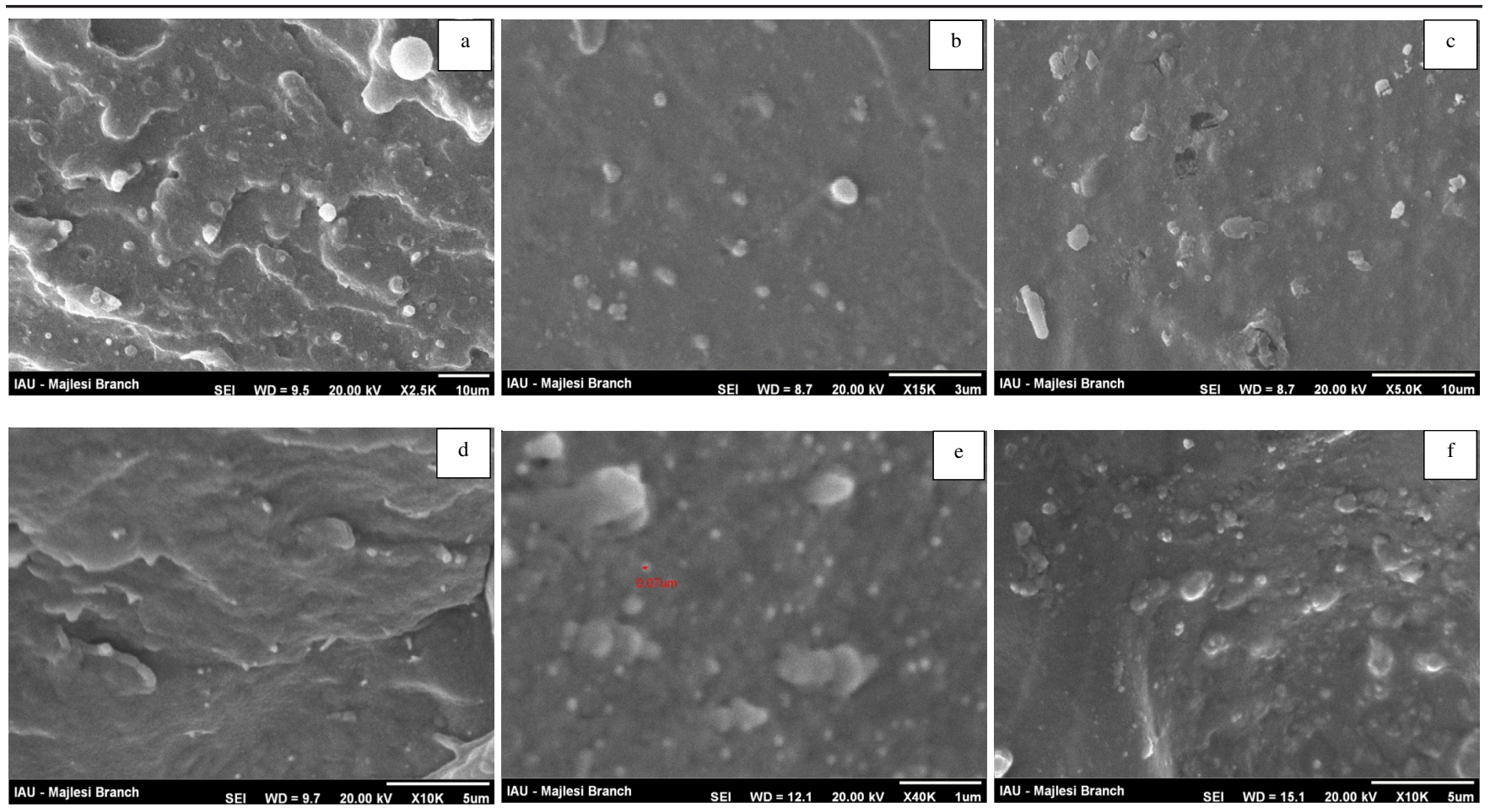

Fig. 1. SEM images of nylon 66 nanocomposites: (a) nylon 66/ATH (b) nylon 66/BHM (c) nylon 66/AO (d) nylon 66/IO (e) nylon 66/NMC (f) nylon 66/MC

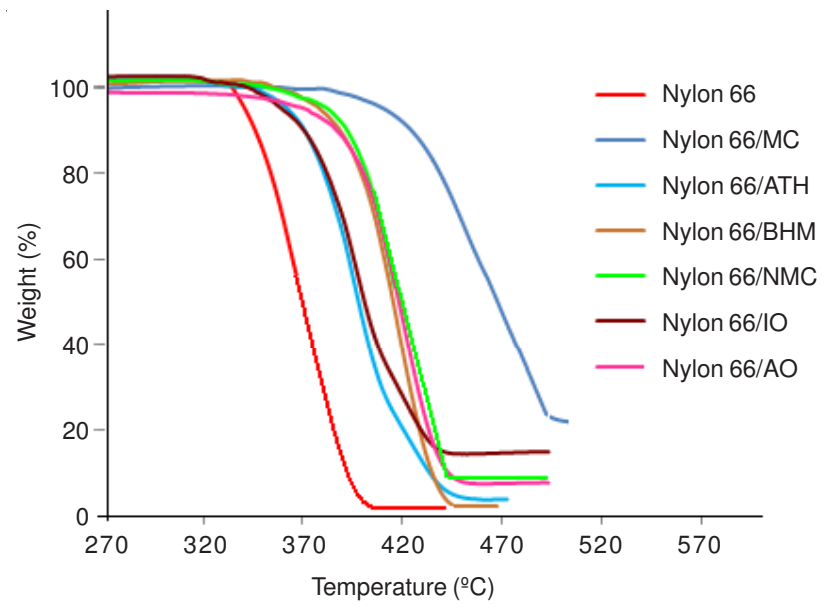

Fig. 2. TGA thermogrphs of nylon 66 and nanocomposites

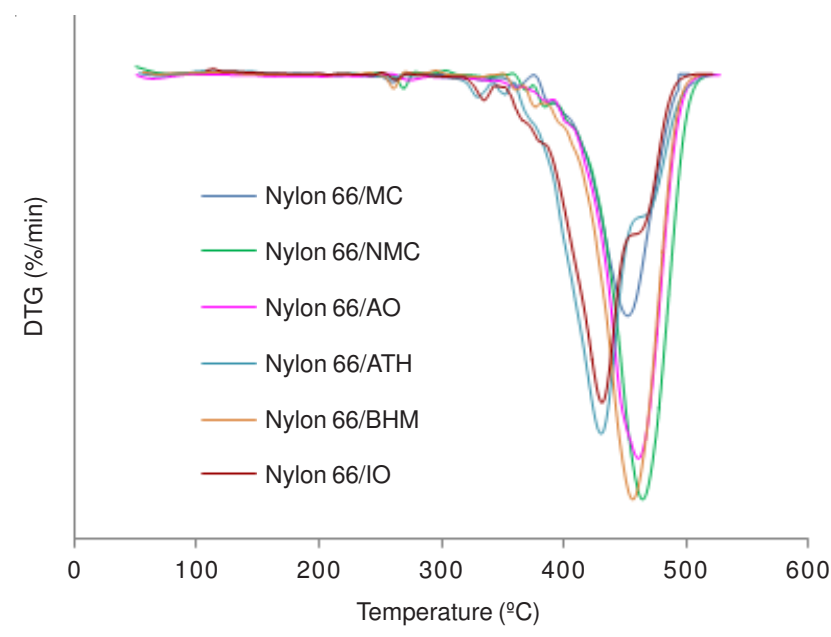

Fig. 3. DTG curves of nylon 66 nanocomposites per cent of residues is the most amount. Nylon 66/NMC and nylon 66/BHM nanocomposites also enhanced thermal stability. It is attributed to the nature of flame retardant nanofillers and good dispersion within the nylon 66 matrix.

Influence of nanofiller type on the flame retardancy of nylon 66: The effect of flame retardant on the LOI of nylon 66 was studied (Fig. 4). Various nanofillers showed different LOI values. As seen two nanoclays had significant effects on the flame retardancy of nylon 66 but the Cloisite 20A was more successful than Cloisite $\mathrm{Na}^{+}$. It is corresponded to the better dispersion and also exfoliation in the nylon 66/MC comparing to that of nylon $66 / \mathrm{NMC}^{10}$. The exfoliated nanocomposites have enhanced thermal stability and flame retardant properties compared with pure nylon 66 . The microcomposites does not show these enhanced thermal stability and flame retardant properties ${ }^{10}$. In polymer/clay nanocomposites, the clay platelets disperse in the polymer matrix in the intercalated multilayered or exfoliated single layered structure. The clay platelets are not totally rigid and parallel to their adjacent macromolecule chains. This special nano-structure leads to a detoured path for the small molecules to spread out when heating. This detour improves the diffusion time of degraded small molecules and thus, improves the barrier effect during combustion of materials. The X-ray photoelectron spectroscopy (XPS) investigation ${ }^{11,12}$ revealed that in polymer/clay nanocomposites, clay breaks down and degrades into aluminosilicate and migrates to the surface. The impermanent barrier can prevent mass transport and isolate the underlying polymer from the thermal energy. While in other nanocomposites the lack of this layered structure of the nanoparticles lead to lower flame retardant properties compared to clay. 


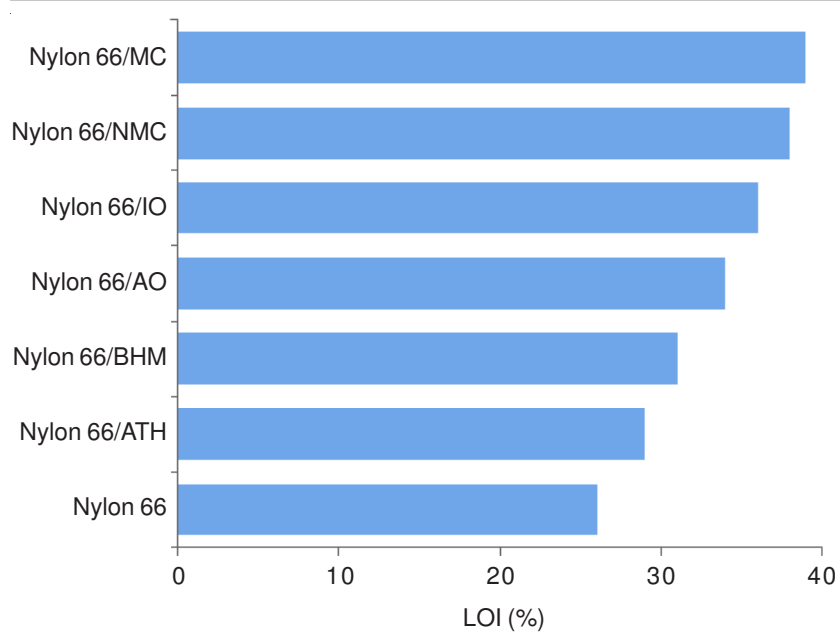

Fig. 4. Comparing the LOI values of nylon 66 and the nanocomposites

Another factor that can affect the flame retardancy is "char formation". Char is a complex material in term of physical, chemical and mechanical structures. It is composed if the mixture of many chemical aromatic aliphatic compounds, often with heteroatom $(\mathrm{O}, \mathrm{N}, \mathrm{P}$ and $\mathrm{S})$. Inorganic substances may be incorporated in the char. Morphologically, char consists of crystalline and amorphous regions. Some physical properties, as well as the mechanical properties, depend on its chemical structure and conditions of preparations. Recently, nanostructured polymer formulations have shown promising perspectives in terms of fire performances acting with different mechanisms. In particular, barrier (char) formation, nanoparticle network and the increase of melt viscosity are recognised as the main general fire retardancy mechanisms of polymer nanocomposites. Technical difficulties in this arise from the need to have a good distribution of the nanoscale filler within the polymer matrix in order to achieve satisfactory results. This target is usually difficult to approach, as seen in the SEM micrographs (Fig. 1), mainly because of high viscosity of the matrix at operative conditions and/or intrinsic chemical features of the host nanofiller that prefer to cluster rather than distribute within the surrounding of the neighbourhood matrix.

Iron oxide nanoparticles had also successful flame retardancy. Iron oxide seems to be the more effective as it also improves the char morphology. Various iron-containing
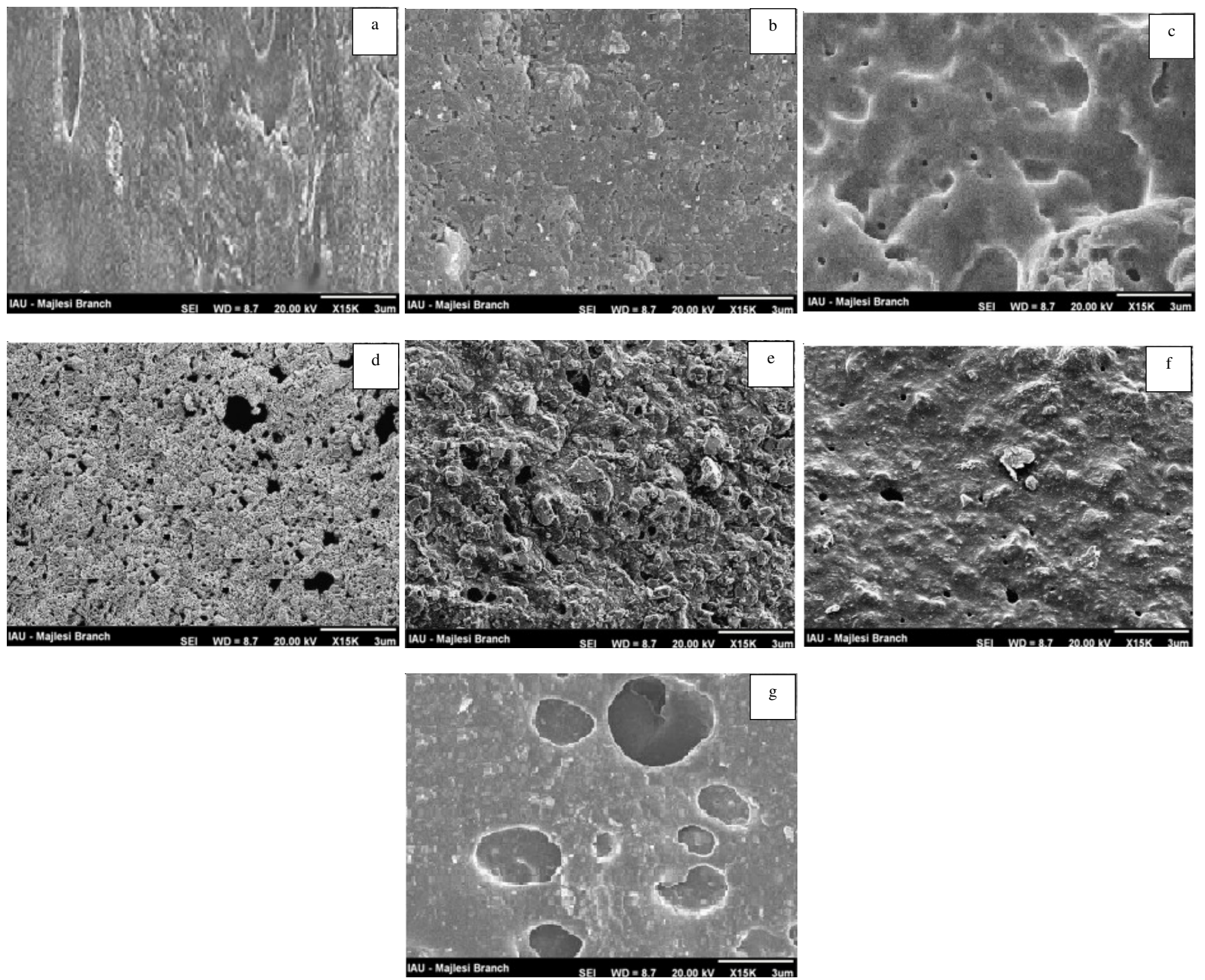

Fig. 5. SEM images of fracture surface of the nylon 66 and nanocomposites' residues for neat nylon 66 and the nanocomposites after combustion (a) nylon 66 (b) nylon 66/NMC (c) nylon 66/MC (d) nylon 66/IO (e) nylon 66/AO (f) nylon 66/ATH (g) nylon 66/BHM 
compounds are beneficial for decreasing the flammability and smoke production, reacting with polymeric carbon containing free-radical sites that may form smoke particles and converting them into char. The formation of this char occurs quickly so the concentration of free radicals drops below the level needed to sustain combustion ${ }^{13}$. $\mathrm{Fe}_{2} \mathrm{O}_{3}$ was the most effective catalyst yielding a graphite of high density ${ }^{14}$. There are several examples in the literature where alkali metals or alkaline earths or other metal salts accelerate the dehydration of polymers containing hydroxyl groups ${ }^{15}$. Table- 1 shows the residue at $500{ }^{\circ} \mathrm{C}$. This parameter has a direct relation with the char formation. As seen this parameter is higher for nylon 66/MC and nylon 66/ IO comparing to other nanocomposites.

The fracture surface of the residues for neat nylon 66 and the nanocomposites after combustion are shown in Fig. 5. As seen nanocomposites containing clay and iron oxide nanoparticles have an obviously honeycomb-like structure in the outer layer. The honeycomb-like structure could provide a good barrier to the transfer of heat and mass, which resulted in the improvement of the flame retardancy of nylon 66 . The formation of the honeycomb-like structure may be attributed to $\mathrm{NH}_{3}$ and other non-combustible gases released from the samples.

\section{Conclusion}

The flame retarded nylon 66 nanocomposites was prepared using different flame retardants in equal amount of nanoparticles. From thermal analysis and LOI results it is concluded that the MC had a good performance to increase thermal stability and flame retardancy comparing to other flame retardant nanoparticles. The residue percent and the morpho$\operatorname{logy}$ of the char are important factors in flame retardancy.
Nanocomposites containing clay and iron oxide nanoparticles have an obviously honeycomb-like structure in the outer layer that could provide a good barrier to the transfer of heat and mass, which resulted in the improvement of the flame retardancy of nylon 66.

\section{ACKNOWLEDGEMENTS}

The work was supported by a grant from the Islamic Azad University, Gachsaran branch.

\section{REFERENCES}

1. (a) J. Lovas, R.D. Suenram and G.T. Fraser, J. Chem. Phys., 88, 722 (1988); (b) A. Okada, M. Kawasumi and T. Kurauchi, Polym. Prep., 28, 447 (1987).

2. E.P. Giannelis, Adv. Mater., 8, 29 (1996).

3. E.P. Giannelis, Appl. Organomet. Chem., 12, 675 (1998).

4. E.P. Giannelis, R. Krishnamoorti and E. Manias, Polym. Confined Environ., 138, 107 (1999).

5. Z. Wang, X. Tang, Z. Yu, P. Guo and H. Song, Chin. J. Polym. Sci., 29, 368 (2011).

6. Y.H. Chen, Q. Wang, W. Yan and H.M. Tang, Polym. Degrad. Stab., 91, 2632 (2006).

7. G.X. Fei, Y. Liu and Q. Wang, Polym. Degrad. Stab., 93, 1351 (2008).

8. S.V. Levchik and E.D. Weil, Polym. Int., 49, 1033 (2000).

9. C.X. Zhao, Y. Liu, D.Y. Wang, D.L. Wang and Y.Z. Wang, Polym. Degrad. Stab., 93, 1323 (2008).

10. L. Song, Y. Hu, Q. He and F. You, Colloid Polym. Sci., 286, 721 (2008).

11. J.X. Du, J. Zhu, C.A. Wilkie and J.Q. Wang, Polym. Degrad. Stab., 77, 377 (2002).

12. J.X. Du, J.Q. Wang, S.P. Su and C.A.Wilkie Polym. Degrad. Stab., 83, 29 (2004).

13. E.G. Acheson, US Patents 558323 (1996).

14. J.C. Bo Kros and R.J. Price, Carbon, 4, 441 (1966).

15. Y. Sekiguchi and F. Shafizadeh, J. Appl. Polym. Sci., 29, 1267 (1984). 